\title{
Correlation of family expressed emotion and frequency of relapse schizophrenia patients
}

I Gusti Agung Ayu Putri Yuni Aryanti, Luh Nyoman Alit Aryani,

\section{Cokorda Bagus Jaya Lesmana}

Department of Psychiatry, Faculty of Medicine Udayana University/Sanglah General Hospital Bali, Indonesia

\section{Cite this article:}

Aryanti IGA Aryani LNA, Lesmana CBJ. Correlation of family expressed emotion and frequency of relapse schizophrenia patients. Journal of Clinical and Cultural Psychiatry. 2020; I (2): 35-37.

\section{Corresponding author:}

\section{dr. Luh Nyoman Alit Aryani, SpKJ}

Department of Psychiatry, Faculty of Medicine Udayana University/Sanglah General Hospital J. Kesehatan No I, Bali 80 I 14, Indonesia alit_aryani@unud.ac.id

\begin{abstract}
Background: Schizophrenia is a severe mental disorder in the psychiatric field, is chronic, and is characterized by recurring relapse. The causative factor that plays an important role is the expressed emotion (EE) of the family. The aim of this study was to determine the expressed emotion scores of families who treated schizophrenic patients at Sanglah Hospital.

Patients and Methods: The study used a cross-sectional analytical method. Measurement of the EE of families using the Family Questionnaire (FQ). Data were analyzed descriptively and used the Spearman correlation test with a significance level of $p<0.05$.

Results: The research participants were 61 families of schizophrenia patients treated at Sanglah Hospital, female (57.4\%), and average age 45 years old. The results showed a correlation between the family's expressed emotion score and the frequency of recurrence of schizophrenic patients in Sanglah Hospital, which was statistically significant $(R=0.611, p<0.001)$. That value shows that the correlation between the family expressed emotion score and the frequency of relapse patients with schizophrenia at Sanglah Hospital has a strong categorical correlation.

Conclusion: There is a significant correlation between the scores of family expressed emotion and the frequency of relapse in schizophrenia patients, where the expressed emotion of families is high, the frequency of relapse in schizophrenia patients will increase.
\end{abstract}

Keywords: expressed emotion, frequency of relapse, schizophrenia, family questionnaire

\section{Introduction}

Schizophrenia is a severe mental disorder in the field of psychiatry, often experiencing stigma from society. This happens because of ignorance or wrong understanding of this mental disorder.1,2 Bali is ranked first in the region with severe psychiatric disorders. As many as $33 \%$ of schizophrenia patients experienced a recurrence, and $12.1 \%$ returned to hospitalization.

A very important contributing factor is the family's expressed emotion (EE) displayed to patients. 3 Western cultural studies suggest there is a strong relationship between high and recurring family EE.4 Research involving families of patients with a diagnosis of schizophrenia, especially in Sanglah Hospital Denpasar, has not been done routinely and deeply. The role of the family is crucial in helping recovery and preventing recurrence, especially patients with schizophrenia. Based on the data above, we are interested in conducting a study of the relationship of family emotional expression with the frequency of schizophrenia recurrence in Sanglah General Hospital. 


\section{Material and Methods}

The study used observational analytic cross-sectional design in Sanglah Hospital in 2019. Inclusion criteria include families of patients with schizophrenia and families who care for schizophrenia patients for the past one year and interact with patients $\geq 8$ hours per day. Exclusion criteria include abnormalities in general medical conditions, any other comorbidities, families who are deaf (hearing loss), mute (speech disorders) and illiteracy, families have a history of mental disorders, and are not willing to be research respondents. We employed a purposive sampling technique for this study.

The research instrument was in the form of a data collection form that contained the characteristics of the sample, and the Family Questionnaire (FQ). The FQ reliability test showed a sensitivity value of $68 \%$ and an accuracy of $78 \%$. Expressed emotion is a perception in verbal and nonverbal forms. They are measured by the Family Questionnaire (FQ).

Recurrence is the appearance of the same symptoms as a mental disorder (schizophrenia), which previously caused hospitalization in the last year, based on reports from families who treated and saw the incident. Relapse is the patient showing the same symptoms as in the past one year. Data were analyzed by computer using the SPSS program.

\section{Result}

Descriptive analysis results found the average of respondents aged 45 years (Table 1). Fifty percent of respondents had EE scores more than 31 . EE respondents in this study were mostly categorized as high $(68.9 \%)$

Table 1. Expression of family emotions caring for schizophrenic patients.

\begin{tabular}{lc}
\hline \multicolumn{1}{c}{ Variables } & $\mathbf{N}(\%)$ \\
\hline Expressed emotion, n(\%) & \\
$\quad$ High & $42(68.9)$ \\
Low & $19(31.1)$ \\
Relapse in the past year & \\
$\quad$ Yes & $43(70.5)$ \\
No & $18(29.5)$ \\
Relapse frequency, median & $1(2)$ \\
(IQR) & \\
\hline
\end{tabular}

Table 2. Relationship between family expressed emotion and relapse frequency.

\begin{tabular}{|c|c|c|c|c|}
\hline & \multicolumn{2}{|c|}{ Relapse in the past year } & \multirow{2}{*}{$\mathbf{R}$} & \multirow{2}{*}{$\mathbf{p}$} \\
\hline & Yes & No & & \\
\hline Expressed emotion & & & 0.611 & $<0.001$ \\
\hline High & $40(95.2)$ & $2(4.8)$ & & \\
\hline Low & $3(15.8)$ & $16(84.2)$ & & \\
\hline
\end{tabular}

Based on the results of the correlation analysis, there is a relationship between family EE and the frequency of recurrence of schizophrenic patients which is statistically significant $(\mathrm{R}=0.611, \mathrm{p}<0.001)$
Spearman's rho correlation coefficient 0,611 shows the relationship of family EE with the frequency of recurrence of schizophrenia patients in Sanglah General Hospital having a correlation that is categorized as strong.

\section{Discussion}

Both verbal and non-verbal $\mathrm{EE}$ is an important aspect in determining the effectiveness of communication with schizophrenic patients.3-5 In this study, a high family EE showed the effectiveness of communication is not good. This happens because the family experiences boredom and confusion in handling patients. Family with low EE improve the prognosis of mental disorders should one of them is schizophrenic patient.6 Similar results were obtained in various countries such as Pakistan, China, and UK ${ }^{8,9}$ EE is an important aspect for the effectiveness of communication and predisposing factors to the recurrence of mental disorders. ${ }^{10,11}$

Respondent's statement $50 \%$ of patients had relapsed more than once, and $70.5 \%$ had relapsed in the past year. This shows that there are still schizophrenia patients who are treated in Sanglah Hospital experiencing recurrence and consequently decreased cognitive and quality of life of the patient.6,9,12-15 High recurrence rate indicates there is a background factor, one of which is EE that influences. Other studies that support the recurrence of patients three times a year, 13 recurrences of schizophrenia patients as much as $43.5 \%$ in a year. ${ }^{15}$

This study found a high family EE with a frequency of recurrence of schizophrenic patients in the last year (95.2\%), compared to low EE $(15.8 \%)$. The relationship of family emotional expression with the recurrence frequency of schizophrenic patients at Sanglah Hospital was statistically significant, with the Spearman's rho correlation coefficient of $0.611(\mathrm{p}<0.001)$. This shows that the correlation between family emotional expression scores with the frequency of recurrence of schizophrenia patients in Sanglah Hospital has a correlation that is categorized as strong.

These results are similar to previous studies stating that high EE in families consistently has a relationship with high recurrence rates of schizophrenic patients. Other studies also mention the frequency of patient recurrence caused by high family EE by $72 \% .{ }^{9}$ The recurrence rate of high schizophrenia patients is caused by several factors, one of which plays a very important role is the high family EE displayed to patients, such as CC and over-involvement or overprotectiveness. Hence, it is necessary to intervene in the family. ${ }^{16,17}$ This study is supported by other studies which state that family height EE is a contributing factor in schizophrenia patients and re-treated. ${ }^{6,8,18}$

The frequency of relapse in schizophrenia patients depends on verbal and nonverbal emotional support, and family and emotional closeness of the patient to the patient. ${ }^{14,15}$ The results indicated that EE was the most related factor for relapse in schizophrenia patients. The implication for health workers is that when treating schizophrenia patients it is better to use a family center care approach, so caring for patients does not only focus on the patient but the family as a 
whole. ${ }^{13}$

The family's EE affects the frequency of relapse in schizophrenia patients. This needs special attention, especially for clinicians. Clinicians need to pay attention to the family's EE and provide psychoeducation to be able to handle the family's EE. Future studies can examine the correlation of each part of emotional expression with the frequency of recurrence.

\section{Conclusion}

There is a strong relationship between family's EE and the frequency of recurrence of schizophrenia in a family that takes care of a schizophrenic family member.

\section{Acknowledgement}

The authors report no conflict of interests.

\section{Reference}

1. Ascher-Svanum H, Zhu B, Faries DE, et al. The cost of relapse and the predictors of relapse in the treatment of schizophrenia. BMC Psychiatry. 2010;10:2. DOI: 10.1186/1471-244X-10-2

2. Chien WT, Leung SF, Yeung FK, et al. Current approaches to treatments for schizophrenia spectrum disorders, part II: psychosocial interventions and patient-focused perspectives in psychiatric care. Neuropsychiatr Dis Treat. 2013;9:1463-1481. DOI: 10.2147/NDT.S49263

3. Bellack AS. Psychosocial treatment in schizophrenia. Dialogues Clin Neurosci. 2001;3(2):136-137.

4. Sadath A, Kumar R, Karlsson M. Expressed Emotion Research in India: A Narrative Review. Indian J Psychol Med. 2019;41(1):18-26. DOI: 10.4103/IJPSYM.IJPSYM_235_18.

5. Weintraub MJ, Hall DL, Carbonella JY, et al. Integrity of Literature on Expressed Emotion and Relapse in Patients with Schizophrenia Verified by a p-Curve Analysis. Fam Process. 2017;56(2):436-444. DOI: 10.1111/famp. 12208

6. Sadock BJ, Sadock VA. Kaplan and Sadock's Comprehensive of Psychiatry. 10th Ed. 2017. Philadelphia: Lippincot Williams and Wilikins; USA.

7. Ikram A, Suhail K, Jafery SZ, et al. Rates of Expressed Emotion in Pakistani Relatives of Patients with Schizophrenia. Israel Journal of Psychiatry and Related Sciences. 2011;48(2):74-81.

8. Wang X, Chen Q, Yang M. Effect of caregivers' expressed emotion on the care burden and rehospitalization rate of schizophrenia. Patient Prefer Adherence. 2017;11:1505-1511. DOI: 10.2147/PPA.S143873.
9. Sadiq S, Suhail K, Gleeson J, et al. Expressed emotion and the course of schizophrenia in Pakistan. Social Psychiatry and Psychiatric Epidemiology. 2017;52(5):587-593. DOI: 10.1007/s00127-017-1357-1.

10. Montero I, Gómez-Beneyto M, Ruiz I, et al. The influence of family expressed emotion on the course of schizophrenia in a sample of Spanish patients. A two-year follow-up study. The British Journal of Psychiatry : the Journal of Mental Science. 1992;161:217-222. DOI: 10.1192/ bjp.161.2.217.

11. Choi YH, Bazarova NN. Sef-Disclosure Characteristics and Motivations in Social Media: Extending the Functional Model to Multiple Social Network Sites. Hum Commun Res. 2015;41:480-500. DOI: 10.1111/ hcre.12053.

12. Grover S, Avasthi A. Clinical Practice Guidelines for the Management of Schizophrenia in Children and Adolescents. Indian J Psychiatry. 2019;61(Suppl 2):277-293. DOI: 10.4103/psychiatry.IndianJPsychiatry_556_18

13. Roseliza-Murni A, Oei TP, Fatimah Y, et al. Schizophrenia relapse in Kuala Lumpur, Malaysia: do relatives' expressed emotion and personality traits matter?. Comprehensive Psychiatry. 2014;55(1):188-198. DOI: 10.1016/j.comppsych.2012.12.026.

14. Chan KW, Wong MH, Hui CL, et al. Perceived risk of relapse and role of medication: Comparison between patients with psychosis and their caregivers. Soc Psychiatry Psychiatr Epidemiol. 2015;50(2):307-15. DOI: 10.1007/s00127-014-0930-0.

15. Mubarak AR, Barber JG. Emotional expressiveness and the quality of life of patients with schizophrenia. Soc Psychiatry Psychiatr Epidemiol. 2003 Jul;38(7):380-4. DOI: 10.1007/s00127-003-0645-0

16. Asmal L, Mall S, Kritzinger J, et al. Family therapy for schizophrenia: cultural challenger and implementation barrier in the South African context. Afr J Psychiatry (Johannesbg). 2011;14(5):367-71. DOI: 10.4314/ ajpsy.v14i5.3.

17. Rosenfarb IF, Triana S, Nuechterlein KH, et al. Expressed emotion and the escalation of depressive symptoms in individuals with recent-onset schizophrenia. Early Interv Psychiatry. 2017;11(4):351-353. DOI: 10.1111/eip.12307.

18. Amaresha AC, Venkatasubramanian G. Expressed emotion in schizophrenia: an overview. Indian J Psychol Med. 2012;34(1):12-20. DOI: 10.4103/0253-7176.96149. 